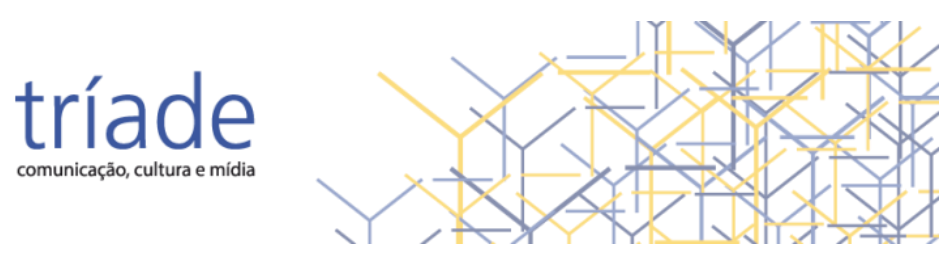

\title{
Das matrizes documentais à memória no futuro
}

\author{
From documental matrices to future memories \\ De las matrices documentales a la memoria del futuro
}

\begin{abstract}
Denize Araujo - Universidade Tuiuti do Paraná | Curitiba | Paraná | Brasil | denizearaujo@hotmail.com I (1) https://orcid.org/0000-0001-6856-509X.
\end{abstract}

\begin{abstract}
Resumo: Este estudo é parte final de minha pesquisa sobre a trajetória dos diários confessionais e autorretratos desde o período do Renascimento até documentários autobiográficos e biopics atuais, e também reflete a pesquisa de meu pós-doutorado sobre éticas e estéticas em imagens das ditaduras. Esta parte do estudo desenvolve dois conceitos: o da imagem-memória e o da imagem-homenagem. O objetivo central é sugerir que documentários poderão ser, no futuro, a memória do passado. O corpus é formado pelo biopic David Lynch, A Vida de um Artista (2016) e pelo autobiográfico Dor e Gloria (2019). A metodologia é baseada no método histórico-dialético de Gadamer. O referencial teórico inclui conceitos de memória de Halbwachs, Sarlo, Le Goff, Ricoeur, Pollak e Nora, além do conceito de desconstrução de Derrida, dos estudos de Arlindo Machado, Nichols e Penafria sobre documentário e subjetividade, e de Bellour e Lebow sobre o eu ficcional/documental.
\end{abstract}

Palavras-chave: Matrizes. Imagem-memória. Imagem-homenagem. Subjetividade. Futuro.

\begin{abstract}
This study is the final part of my research about the trajectory of confessional diaries and (auto) portraits since Renaissance up to nowadays biopics and autobiographical documentaries, and also refers to my post-doctorate about ethics and aesthetics in dictatorships images. This part of the study develops two concepts: memory-image and tribute-image. The mais objective is to suggest that documentaries can be, in future times, a memory of the past. The corpus includes the biopic David Lynch, The Art Life (2016) and Pain and Glory (2019). The methodology is based on the dialectic-historian method of Gadamer. The theoretical references include concepts of memory by Halbwachs, Sarlo, Le Goff, Pollak and Nora, and also Derrida's deconstruction concept, studies by Arlindo Machado, Nichols and Penafria about documentary and subjectivity, and Bellour's and Lebow's fictional/documental.
\end{abstract}

Keywords: Matrice. Memory-image. Tribute-image. Subjectivity. Future. 
Resumen: Este estudio es una parte final de mi investigación sobre la trayectoria de los diarios confesionales y autorretratos desde el período del Renacimiento hasta los documentales autobiográficos y biopics actuales, y también refleja mi investigación postdoctoral sobre ética y estética en imágenes de dictaduras. Esta parte del estudio desarrolla dos conceptos: la imagen-memoria y la imagentributo. El objetivo principal es sugerir que los documentales pueden, en el futuro, ser la memoria del pasado. El corpus está formado por el biopic David Lynch, La vida de un artista (2016) y la autobiográfica Dor e Glória (2019). La metodología se basa en el método histórico-dialéctico de Gadamer. El marco teórico incluye conceptos de memoria de Halbwachs, Sarlo, Le Goff, Ricoeur, Pollak y Nora, además del concepto de deconstrucción de Derrida, los estudios de Arlindo Machado, Nichols y Penafria sobre documental y subjetividad, y Bellour y Lebow sobre el yo de ficción/documental.

Palabras clave: Matrices. Memoria de imagen. Imagen-tributo. Subjetividad. Futuro. 


\section{Introdução: contextualização da pesquisa}

Este estudo é a parte final de minha pesquisa sobre a trajetória dos diários confessionais e autorretratos desde o período do Renascimento até documentários autobiográficos e biopics atuais, e também reflete a pesquisa de meu pós-doutorado sobre éticas e estéticas em imagens das ditaduras. A sedução pela imagem sempre foi cultuada por pintores e fotógrafos, que tinham como meta retratar a realeza ou mesmo se auto retratar. Todas essas imagens fazem parte do acervo histórico e artístico que ilustra o passado e que, consideradas as devidas conotações, hoje é revisitado e reconfigurado através dos diversos mecanismos tecnológicos que continuam apreciando famosos por seus feitos e estimulando a cultura dos selfies.

A premissa de minha pesquisa é que os documentários autobiográficos e biopics são uma nova versão dos antigos diários confessionais e dos autorretratos e retratos pictóricos por encomenda, cujas imagens sempre seduziram realezas e mesmo retratistas. $\mathrm{Na}$ contemporaneidade, há uma tendência crescente em compartilhar opiniões e ideias, em expor personalidades famosas e em se posicionar diante das câmeras, confessando visões de vida. A pesquisa tem como objetivo geral analisar a trajetória e as convergências entre os diários, autorretratos e retratos pictóricos e os documentários biopics e autobiográficos (ou auto documentários).

Um dos objetivos específicos da pesquisa é verificar como a sedução da imagem estimulou a criação de obras de arte com imagem fixa, em pinturas e esculturas, passando em seguida à fotografia e depois à imagem em movimento, sempre exercendo um fascínio que atualmente se materializa com a tecnologia digital. Outro objetivo específico é argumentar que a subjetividade, inerente ao documentário mesmo quando este se propõe a ser fiel aos fatos que expõe, é parte integrante de versões da factualidade que poderão se tornar, no futuro, a memória do passado. A pesquisa se justifica por aprofundar o conhecimento sobre imagens documentais que serão relevantes no futuro, embora carreguem consigo subjetividades que confirmam a asserção de que verdades e realidades são plurais e dependentes do repertório de quem as está analisando. 
Para maior relevância, em trabalhos anteriores já foram selecionados alguns filmes clássicos e outros experimentais para verificar como se comporta a intertextualidade subjetiva nos dois tipos e como a memória atua em situações ímpares. Um dos documentários autobiográficos estudados foi As Praias de Agnès (2008), de Agnès Varda, que se autobiografia e interage, narrando fatos de sua vida e de seus pensamentos e reflexões com estética intertextual, não só em seu filme As praias, mas em outros onde se veste como as ceifadoras ou recria Magritte, em sua famosa obra "Os amantes".

Após analisar As Praias de Agnès (2008), da cineasta Agnès Varda, Santiago (2007), de João Moreira Salles, e Elena (2016), de Petra Costa, em outros momentos de pesquisa com abordagens diferentes, constatei alguns elementos comuns aos três filmes, como a representação do reconhecimento e do tributo, em elementos intertextuais. Petra Costa, apesar de falar de sua irmã, se identifica tanto com a mesma que comenta que parecem ser uma só. Assim há traços de autobiografia em seu filme, que denomino de "selfie-biopic". Com passagens emocionais e íntimas, a diretora revisita os passos de sua irmã em New York, criando imagens na água que remetem à Ofélia de Shakespeare perpetuada por Millet. Varda apresenta seus amigos, seu comprometimento às reivindicações sociais e seus ídolos, explicitando que sua autobiografia é uma maneira de mostrar seu eu para sua família e amigos. Devido aos elementos, seu filme pode ser chamado de "autobiográfico-intertextual". João Moreira Salles, após refletir muito sobre a produção de seu docbiopic, reconstitui cenas anteriores que havia feito com Santiago, produzindo um "doc-tributo", dedicado ao mordomo que acompanhou sua família por 30 anos.

Apesar de considerar as origens do retrato pictórico de grande relevância, o recorte para a pesquisa tem início no período do 4U Renascimento, no final do século XIV, por ser uma passagem da Idade Média à Moderna, com grande afluência dos auto-retratos e dos retratos encomendados pelos reis e outros títulos da nobreza, e a trajetória da imagem segue até o ano de 1.900. Minha ênfase é a evolução dos retratos pictóricos que hoje se manifesta em documentários que retratam pessoas que protagonizaram papéis importantes, além de outras que 
foram admiradas e reconhecidas por feitos políticos ou científicos, e ainda outras que se auto-retrataram.

Apesar do embasamento em minhas pesquisas anteriores, neste texto, o foco é outro. Enquanto nas análises anteriores o enfoque foi direcionado às intertextualidades subjetivas, a ênfase deste trabalho é a sedução da imagem, com especial destaque para os conceitos de imagemmemória e imagem-homenagem, e a origem e trajetória das mesmas, sempre considerando que, assim como temos obras que nos trazem hoje as memórias do passado, teremos no futuro as obras de hoje, que serão estudadas e tomadas como verossimilhança de nosso tempo.

O corpus é formado por dois filmes: o documentário biopic David Lynch, A Vida de um Artista (2016) e o documentário autobiográfico Dor e Glória (2019). Como metodologia, a histórico-dialética de Gadamer me pareceu ser a mais adequada. O referencial teórico inclui conceitos de memória de Halbwachs, Sarlo, Le Goff, Ricoeur, Pollack e Nora, além do conceito de desconstrução de Derrida e dos conceitos de Bellour e Lebow sobre o eu ficcional/documental. Os diversos pontos de vista dos autores citados oferecem conceitos de memória relacionados à subjetividade, à memória coletiva e afetiva, à identidade social, à história e ao esquecimento, que são temas essenciais deste estudo. Arlindo Machado, Bill Nichols e Manuela Penafria contribuem com seus estudos sobre documentário e subjetividade, essenciais para esta análise.

Os conceitos da moldura referencial respondem às minhas hipóteses sobre a relevância da memória, seja ela coletiva ou afetiva, evitando o esquecimento, ou seja, comprovam minha argumentação de que atualmente cineastas e fotógrafos continuam produzindo imagens, especialmente após o advento das possibilidades múltiplas que as tecnologias mais recentes proporcionam.

Depois de minhas interações na disciplina de Jacques Derrida, (U) cursada em Irvine, Califórnia, sobre sua teoria da desconstrução, suponho que a subjetividade seja inerente a qualquer processo fílmico, mesmo considerando que alguns teóricos argumentam que certos documentários são expressões genuínas da factualidade, termo que uso em lugar de "realidade", para não incorrer em uma visão simplista ou reducionista e por reconhecer, como sugere Jacques Derrida, que não há uma única 


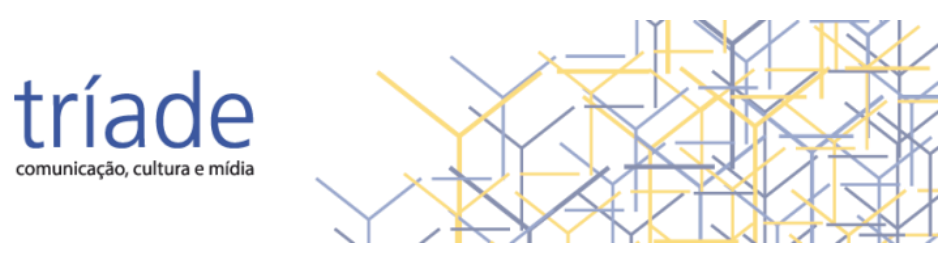

realidade ou verdade e sim realidades e verdades inerentes a cada um de nós.

\section{Trajetória dos (auto) retratos}

Um dos exemplos do século XIV é o retrato de João II, o Bom (1360), de autoria desconhecida, hoje exposto no Museu do Louvre (Fig. 1). Outro exemplo é o retrato de George Washington (1796), executado por Gilbert Stuart (Fig. 2). Apesar da sedução que o retrato pictórico implícita, Oliver Cromwell exigiu que o seu fosse bem realista, com rugas e imperfeições próprias de seu perfil (Fig. 3). Já nesta simples escolha de alguns retratos, pode-se notar que Cromwell, ao contrário de outros, preferiu que seu retrato fosse mais autêntico. Um dos autorretratos mais significativos foi o de Albrecht Durer, pintor renascentista alemão. Em seu Self-Portrait, de 1498, que está no Museu do Prado, o artista olha diretamente para o espectador (Fig. 4). Outro autorretrato famoso é o de Vincent van Gogh (Fig. 5), que fez muitos autorretratos, inclusive depois de ter cortado parte de sua orelha, segundo a lenda, quando esta não se encaixava em seu autorretrato.

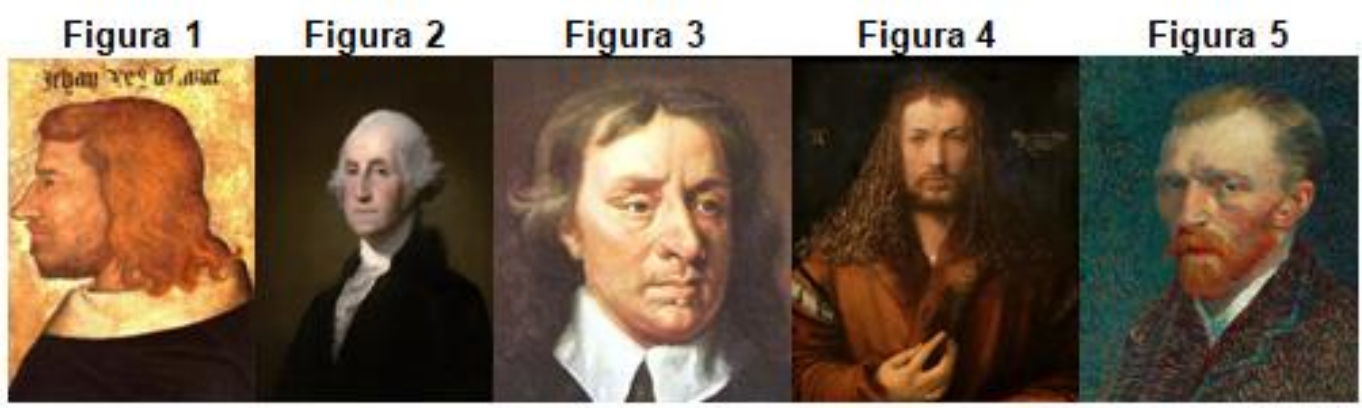

Fonte: Google imagens.

Meu argumento é que a sedução da imagem, iniciada há muito

(U) tempo, hoje está igualmente presente e se traduz em documentários selfies ou autobiográficos e biopics, depois de ter passado pela era da fotografia, ter se revelado em imagens em movimento e se reproduzido em imagens digitais onde a sedução pode ser ainda mais disseminada com o uso de suportes midiáticos eficazes. Além disso, a subjetividade, 


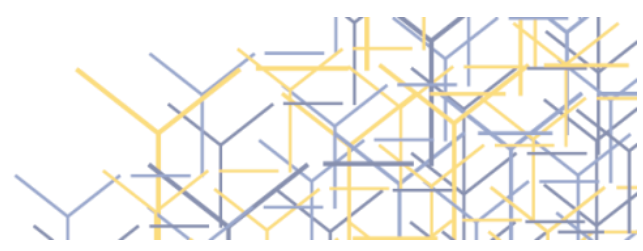

que poderia ser uma característica dos retratos pictóricos que não tinham como reproduzir exatamente os retratados, passou a ser mais objetiva com o advento da fotografia e depois do cinema, e se tornou hiperreal com as novas mídias. As imagens se tornaram portadoras de novas possibilidades, podendo demonstrar parcialmente o interior dos que para elas posam, mesmo estáticas, porém em movimento, como nos Screen Tests de Andy Warhol (1975) (Fig. 6). A pergunta de Mitchell (2005) "o que as imagens realmente querem" pode ser questionada por sua relevância neste caso.

Figura 6 - Screen Tests, Andy Warhol
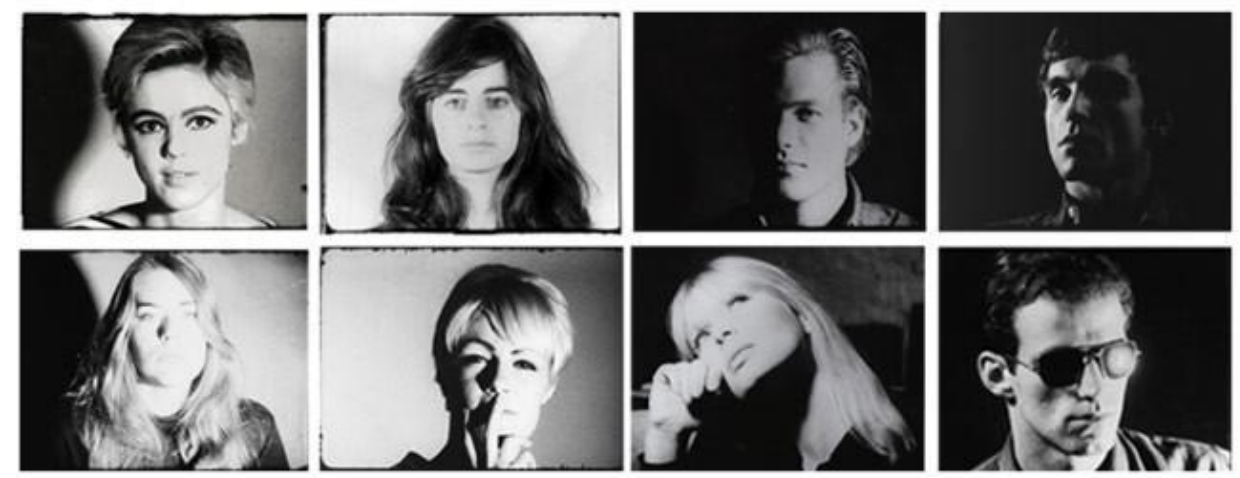

Fonte: Frame Screen Tests.

No caso do filme documentário 48 , da diretora portuguesa Susana de Sousa Dias, as imagens abaixo (Fig. 7) são portadoras das torturas da ditadura. Aparentemente estáticos, os retratos apresentam movimentos mínimos enquanto seus relatos nos informam seus sofrimentos. 


\section{tríade}

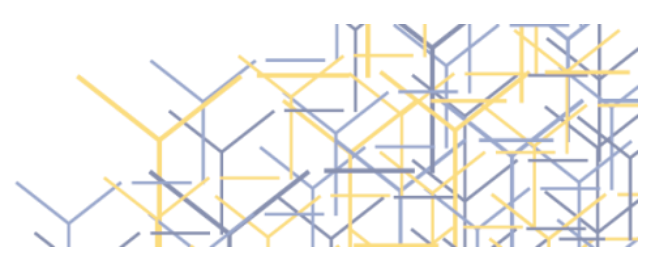

Figura 7 - Filme Documentário 48, Susana de Sousa Dias

Fonte: Frame Documentário 48.

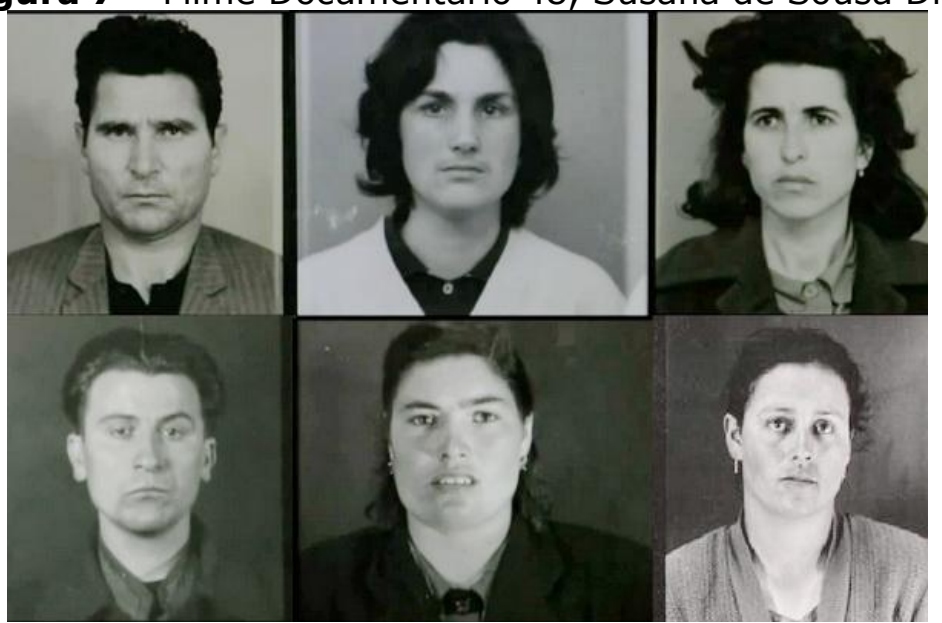

Os Screen Tests de Andy Warhol foram inspirados nos 13 mais procurados do Departamento de Polícia de New York em 1962. O título do filme Documentário 48 de Susana de Sousa Dias se refere aos 48 anos do governo de Salazar em Portugal. Os retratos de Andy Warhol e de Susana de Sousa Dias podem ser associados pelo fato de serem estáticos com mínimos movimentos: os de Warhol foram filmados por três minutos e os do filme 48 tem a duração dos relatos das torturas, com mínimos movimentos dos olhos ou das faces, acompanhando as descrições das vozes. Ambas as técnicas implicitam imagens que continuam a nos desafiar a desvendar seus interiores.

Além do fato dos pintores retratarem famosos e produzirem seus próprios autorretratos e do advento da fotografia, que intensificou e facilitou os retratos e autorretratos, proponho que a tradição dos diários confessionais está sendo reformulada na contemporaneidade, na exposição do "eu", agora público e não mais privado. Há diários <U importantes, especialmente "Les Confessions", onde Jean Jacques Rousseau reúne 53 anos de sua vida, até 1765. Benjamin Franklin também escreveu sua "Autobiografia", em 1793, uma coleção de textos sobre seus experimentos, sobre a perfeição moral e sobre identidade social. Ambos os autores são relevantes, Rousseau por ser considerado o 
primeiro a escrever uma autobiografia e Franklin por ter escrito o primeiro bestseller americano. Com a tecnologia digital e a exacerbação da cultura do eu, houve um aumento considerável do uso das redes sociais. O uso exacerbado da cultura do eu pode influir na memória recriada e representada em documentários.

A tecnologia digital, por um lado, tem incentivado novos realizadores a uma exposição constante nas redes e a uma sedução pela exposição de seus conceitos em curtas de rápida finalização, como no vídeo Leave Britney Alone (2007), de Chris Crocker, que viralizou em pouco tempo. Por outro lado, documentaristas, impulsionados por razões diversas, decidiram homenagear pesquisadores relevantes, como no biopic Steve Jobs (2015), ou revelar suas vidas, como nos documentários autobiográficos Talk to me (2007), de Mark Craig e Wide Awake (2006) de Alan Berliner. Sugiro também que os novos suportes, como iphones, tablets, ipads e similares, colaboraram para a disseminação imediata e as possibilidades de ver documentários fora das salas de cinema.

Problematizando essa produção fílmica de documentários autobiográficos e de biopics, acredito que a memória de ídolos ou de si mesmos é, em muitas obras, registrada de maneira subjetiva, enfatizando certos elementos, negligenciando outros e enfocando cenas menores, chegando ao extremo de provocar processos pelo uso indevido das permissões do uso da imagem por familiares, como em Amy (2015) e Grace of Monaco (2014), dois biopics que extrapolaram as permissões das famílias. Por outro lado, devemos considerar que nem mesmo documentários clássicos, como Nanook of the North (1922), do

(U) antropólogo Robert Flaherty, foram fiéis ao que se denomina de "fato real".

A representação tem certa autonomia, muitas vezes criando documentários híbridos que serão fonte de pesquisa futuramente e memória a ser lembrada, assim como hoje temos filmes como Getúlio (2014), que são repletos de subjetividades, mas pretendem nos oferecer 
novas interpretações em relação à memória coletiva. Acredito que o termo "memória-metamorfose" pode explicar como, no presente, podemos entender melhor o passado e construir novas memórias. Denominei esta memória mutante de "memória-metamorfose" por considerar que esta reflexão sobre memórias que se formam ao longo dos anos impede que tenhamos uma interpretação única e unilateral dos fatos passados, permitindo um equilíbrio dialógico que oferece possibilidades de reconstituição de lembranças, indo além do que descreve Hans-Georg Gadamer, em sua concepção "tese-antítese-síntese", ou seja, contemplando uma perspectiva mais abrangente, incluindo possibilidades de intervenção, em processo de metamorfose, permitindo que, após a aquisição de um repertório mais amplo, possam ocorrer outras interpretações em substituição às antigas. Como metodologia, acredito que a escolha mais relevante é a adoção do método histórico-dialético de Gadamer por sua flexibilidade de interações na linha do tempo e de inserções de novos componentes que podem facilitar a análise dos subtemas propostos.

\section{Retratos e biopics como memória e homenagem}

Retratos e filmes biográficos, aqui denominados biopics, além de serem fontes de memória no futuro, muitas vezes podem ser considerados homenagens aos seus retratados, por sua relevância, como no caso do retrato de George Washington, executado por Gilbert Stuart, que apareceu no bilhete de um dólar dos Estados Unidos durante mais de

(I) um século.

Em David Lynch, A Vida de um Artista (2016), os diretores Jon Nguyen, Rick Barnes e Olivia Neergaard-Holm, seduzidos pela visão do artista, praticamente desaparecem, deixando Lynch em primeiro plano (Fig. 8), como se ele estivesse pousando para a câmera, assim como George Washington posou para seu retratista. 


\section{tríade}

Figura 8 - David Lynch, A Vida de um Artista (2016)

Fonte: Frame David Lynch, A Vida de um Artista (2016).

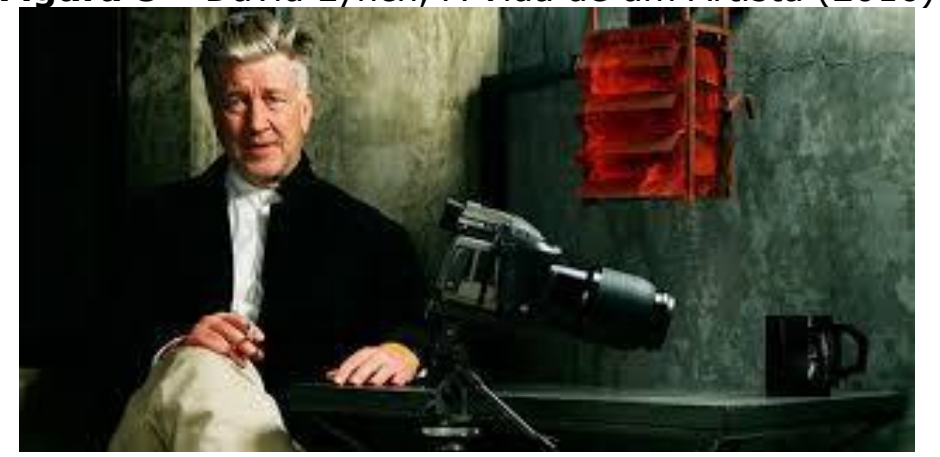

O documentário-homenagem discorre sobre as experiências artísticas de Lynch, enfatizando o campo da arte, até o momento em que o artista vê uma imagem em movimento (devido ao vento) em uma de suas obras, imagem esta que o leva a pensar em produzir filmes. A relevância do documentário é, em parte, sobre este retrato de um artista que é mais conhecido por seus filmes do que por suas pinturas. A homenagem dos diretores ao revelar as origens do processo cinematográfico é importante para a compreensão da obra fílmica de Lynch. Como cita Gastón Bachelard, em "A Poética do Espaço":

As grandes imagens têm ao mesmo tempo uma história e uma pré-história. São sempre lembrança e lenda ao mesmo tempo. Nunca se vive a imagem em primeira instância. Qualquer grande imagem tem um fundo onírico insondável e é sobre esse que o passado pessoal põe cores particulares. (BACHELARD, 1993, p. 50).

Ao exibir imagens de Lynch em sua infância e juventude, seguidas por imagens de suas pinturas, os diretores criaram uma pré-história que explica o futuro do cineasta. O onírico e o sombrio estão lá, nessa préhistória que vai revisitar suas origens na filmografia de Lynch. Assim como os retratos representam maneiras de conhecimento do passado no presente, os filmes de hoje representarão no futuro um canal de apreensão sobre cineastas que não mais estarão presentes. Jacques Le Goff, em seu "História e Memória", nos oferece seus comentários: 


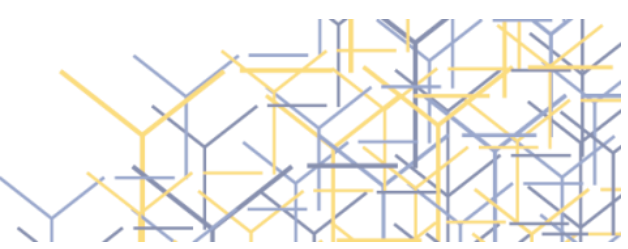

A distinção passado/presente que aqui nos ocupa é a que existe na consciência coletiva, em especial na consciência social histórica. Mas torna-se necessário, antes de mais nada, chamar a atenção para a pertinência desta posição e evocar o par passado/presente sob outras perspectivas, que ultrapassam as da memória coletiva e da história. De fato, a realidade da percepção e divisão do tempo em função de um antes e um depois não se limita, em nível individual ou coletivo, à oposição presente/passado: devemos acrescentar-Ihe uma terceira dimensão, o futuro. (LE GOFF, 2013, p. 209).

Um dos objetivos deste estudo é, justamente, a memória que os biopics deixarão para o futuro. Se os biopics prestaram homenagem a cineastas, os mesmos serão lembrados não só por seus filmes, mas também pelas suas imagens retratadas. David Lynch, A Vida de um Artista, será uma fonte de referência relevante para explicar os temas insólitos da obra fílmica que está por vir no biopic. A sedução e a subjetividade, ambas implícitas no documentário, são exploradas em detalhe, justificando futuras construções. Lynch foi seduzido pelo absurdo e pelo inusitado, pelo surrealismo emergente já em suas primeiras experiências artísticas, que desgostaram seu pai, mas que, por sua vez, nos seduzem em seus filmes como seduziram os diretores em sua decisão de filmar seus desenhos e suas criações.

Segundo a pesquisadora Mirian Tavares, em seu artigo "Do surrealismo de David Lynch", a frase dita por Lynch "If everything is real... then nothing is real as well", em 1973, e publicada pela primeira vez dez anos depois no L.A. Reader,

[...] acaba por definir toda a obra de um autor que, desde seus primeiros trabalhos, recusou-se a mergulhar num universo de imagens convencionais, apostando sempre no absurdo e no maravilhoso. E é esta sua obstinação que o torna um dos poucos artistas contemporâneos que podem ser considerados verdadeira e coerentemente surrealistas. (TAVARES, 2009, p. 100). 


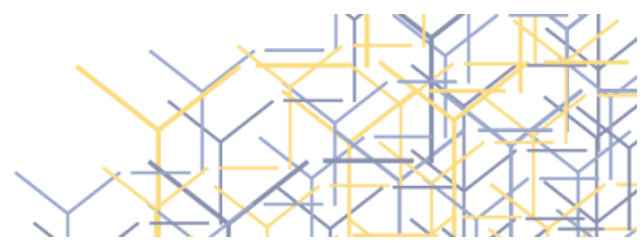

Tavares menciona que "o termo surrealismo perdeu, ao longo dos anos, o seu sentido original, sendo usado muitas vezes de maneira incorreta ou pouco séria por muitos que consideram surrealista qualquer coisa que se aproxime do absurdo ou que se mova contra a correnteza do cotidiano" (TAVARES, 2009, p. 100). Endossando a observação, acredito que um dos méritos do documentário sobre David Lynch é exatamente a homenagem prestada ao surrealismo, como uma maneira de relembrar esta corrente artística tão inovadora. "Ao contrário do que se costuma pensar", continua Tavares,

[...] os surrealistas não queriam fugir do cotidiano; queriam, isto sim, virá-lo pelo avesso, mostrar as suas entranhas através de procedimentos diversos que tornavam o real estranho [...]. O que os surrealistas propunham era desmontar a construção da lógica narrativa (tanto no nível sintático como no semântico). (TAVARES, 2009, p. 101).

Talvez o conceito de desconstrução de Derrida, em seu famoso "A Farmácia de Platão", possa ser aplicado aqui para explicar o processo das imagens de Lynch já em suas pinturas e, mais tarde em seus filmes. Derrida sugere o desfazer e o refazer, em sua citação poética:

O pano envolvendo o pano. Séculos para desfazer o pano. Reconstituindo-o, também, como um organismo. Regenerando indefinidamente seu tecido por detrás do rastro cortante $[\ldots]$. É preciso empenhar-se para pensar isso: que não se trata de bordar, a não ser que se considere que saber bordar é ainda se achar seguindo o fio dado. (DERRIDA, 1997, p. 7).

No documentário David Lynch, A Vida de um Artista, o próprio artista desvenda parte de seu universo criativo, que segue o desfazer e o refazer de Derrida. O documentário cria uma memória sobre o artista e a obra que reconhece seu talento. 


\section{Conceitos de imagem-memória e imagem-homenagem}

Para analisar a imagem-memória, meu referencial teórico inclui os conceitos de Beatriz Sarlo sobre memória subjetiva, de Maurice Halbwachs sobre memória coletiva, de Jacques Le Goff sobre memória e história, de Paul Ricoeur sobre memória e esquecimento, de Michael Pollak sobre memória e identidade social e de Pierre Nora sobre memória afetiva. Sarlo, em seu "Tempo passado: cultura da memória e guinada subjetiva", acredita que "os discursos da memória, tão impregnados de ideologias como os da história, não se submetem, como os da disciplina histórica, a um controle que ocorra numa esfera pública separada da subjetividade" (SARLO, 2007, p. 67). Se a subjetividade permeia todos os discursos, como cita Derrida em seu conceito de desconstrução, temos que admitir que, mesmo subjetivos, documentários biopics nos oferecem uma imagem, talvez híbrida e em parte ficcional, de nomes importantes que devem ser lembrados no futuro, como é o caso de David Lynch. Le Goff, em seu livro "História e Memória", corrobora com o pressuposto, refletindo que "a memória, onde cresce a história, que por sua vez a alimenta, procura salvar o passado para servir o presente e o futuro" (LE GOFF, 2013, p. 477), o que justifica meu argumento de que certas obras serão fontes de referência no futuro. Halbwachs, em seu livro "A Memória Coletiva", cita que "a história é a compilação dos fatos que ocuparam maior lugar na memória dos homens" (HALBWACHS, 2013, p. 100), pensamento que também concorre para o caso em questão, especialmente na trajetória de obras sobre retratados relevantes que, com

(U) seus fatos ou ideias, são homenageados e deixam seus legados para a história da humanidade. Ricoeur, em seu livro "A memória, a história e o esquecimento", reflete: "De um lado, o esquecimento nos amedronta. Não estamos condenados a esquecer tudo? De outro, saudamos com uma pequena felicidade o retorno de um fragmento do passado arrancado, como se diz, ao esquecimento" (RICOUER, 2010, p. 427). Se o futuro é 
uma continuidade, não devemos esquecer fatos passados e suas representações, embora meu conceito de memória-metamorfose possa se tornar relevante e indicativo do que Pierre Nora sugere, em seu "Entre memória e história":

A memória é a vida, sempre carregada por grupos vivos e, nesse sentido, ela está em permanente evolução, aberta à dialética da lembrança e do esquecimento, inconsciente de suas deformações sucessivas, vulnerável a todos os usos e manipulações, suscetível de longas latências e de repentinas revitalizações. (NORA, 1993, p. XIX).

Michael Pollak complementa, em "Memória e identidade social": "Podemos portanto dizer que a memória é um elemento constituinte do sentimento de identidade, tanto individual como coletiva, na medida em que ela é também um fator extremamente importante do sentimento de continuidade e de coerência de uma pessoa ou de um grupo em sua reconstrução de si" (POLLAK, 1992, p. 200).

\section{Dos auto-retratos e diários confessionais aos documentários autobiográficos}

Diversos pintores se autorretrataram. Um dos mais famosos, Diego Velázquez, em seu "Las Meninas" (1656), criou um contexto original, sendo o retratista da família real, colocando no centro do quadro o reflexo no espelho, onde estão o rei e a rainha. O pintor espanhol se autorretrata, pintando. Vincent van Gogh fez diversos autorretratos, inclusive justificando que havia cortado sua orelha porque a mesma não se encaixava em seu autorretrato. Self-Portrait, de 1498, é outro autorretrato significativo, de Albrecht Durer, pintor renascentista alemão, que olha diretamente para o espectador. Por outro lado, escritores também exibiram suas vidas em seus diários confessionais. Jean Jacques Rousseau reuniu 53 anos de sua vida, até 1765, em seu "Les 


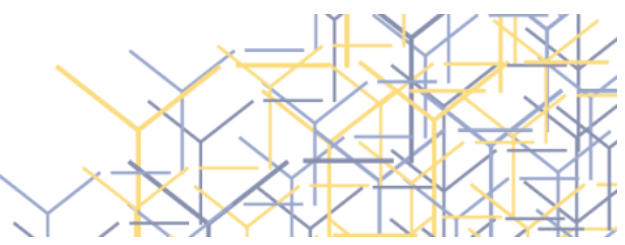

Confessions". Benjamin Franklin e Jean Paul Sartre também escreveram suas memórias, em 1793 e 1963, respectivamente. Os filmes ou documentários autobiográficos, reunindo imagem e palavra, expressam desejos de seus criadores.

Selecionei o filme Dor e Glória, de Pedro Almodóvar, como representante dos documentários autobiográficos, pela atitude de seu roteirista e diretor, que não negou sua autobiografia, ao mencionar que Salvador Mallo (Antonio Banderas) é seu alter ego, que já teve seus momentos de glória e agora sofre as dores inerentes ao avanço da idade. O título reflete exatamente a trajetória da glória e da dor, em momentos não lineares, relembrando a infância já artística, e o primeiro latente sinal da homossexualidade, fazendo-o desmaiar ao ver um corpo masculino nu, sofrendo com a noção do pecado. Poderíamos dizer que a diegese é rizomática, com seus platôs e linhas de fuga, como Deleuze e Guattari (1980) descrevem, em seu conceito de rizoma. Poderíamos dizer também que o documentário é de memória e de homenagem: memória de sua vida e homenagem aos seus sucessos, à sua glória.

Figura 9 - filme Dor e Glória, Pedro Almodóvar

Fonte: Frame Dor e Glória.

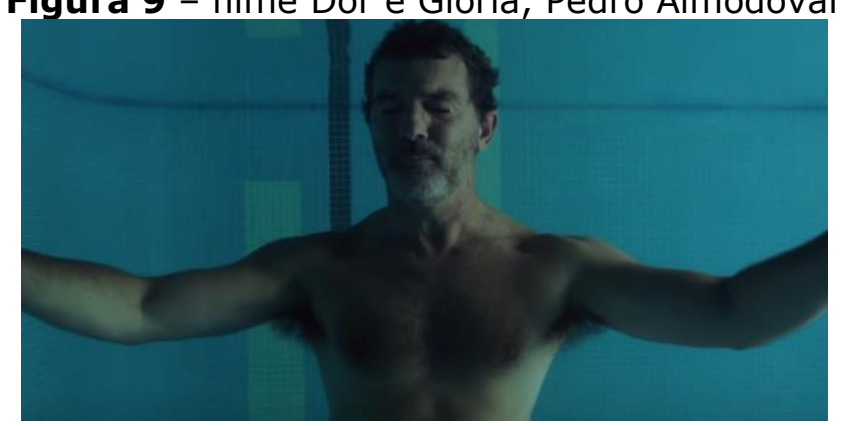

De exasperado e intempestivo, Salvador/Banderas/Almodóvar se torna mais brando e se auto analisa, submerso na piscina, reconhecendo suas falhas. Melancólico e com a carreira em declínio, perdoa Alberto Crespo, com quem havia rompido relações, e compartilha com o mesmo algo novo, a heroína, que pode significar o desejo de se perder ou uma 
volta à amizade com o ator. Interage com sensibilidade com seus amores e permite que suas fraquezas no presente se manifestem em pequenos gestos. Almodóvar e Banderas, diretor/roteirista e ator se entendem perfeitamente, ambos mais maduros e mais sofridos, seja por dores físicas ou por momentos difíceis em suas carreiras. Formam um autorretrato duplo, como um espelho, onde um pode ver no outro suas próprias dores e glórias.

Raymond Bellour, em seu "Eye For I: Vídeo self-portraits", observa que o autorretrato se distingue da autobiografia pela ausência da história, pendendo para o analógico, o metafórico e o poético bem mais do que a narrativa, sendo que sua coerência se mostra em um sistema de lembranças e entrelaçamentos, aparentando descontinuidade, justaposição na montagem (BELLOUR, 1989, p. 8-9).

Contudo, se os autorretratos do passado refletem as faces de seus autores e os diários confessionais nos oferecem suas palavras e descrições, o documentário de Almodóvar vai além: por vezes nos mostra um autorretrato, em imagens, outras vezes um relato autobiográfico revelando uma memória de seu passado fílmico e pessoal, e ainda outras vezes oferece uma reflexão sobre suas escolhas e personalidade e uma permissão para partilharmos de suas indecisões, de seu isolamento e de sua força de vontade para voltar do fundo da piscina à sua borda, já reconciliado com seu passado e presente.

Dor e Glória se autorretrata, se autoanalisa, é um filme de autobiografia, além de ser um documentário de reconciliação. Sem esta última, o cineasta não poderia viver. Como em suas próprias palavras o

(U cineasta afirma: "sem filmar minha vida não faria sentido". Em Dor e Glória o cineasta recria o passado através da memória de fatos marcantes, faz homenagens, revê sua antiga paixão, se penitencia, abre seu coração e oferece um filme de redenção, de imagens-memória e imagens-homenagem. 
Indo além, o filme reitera a asserção de que obras de arte são eternas, mesmo sem a presença física de seus criadores, sendo este o argumento deste meu texto. No futuro, serão fontes de conhecimento obras como este documentário que, por sua vez, nos remete à memória do neo realismo em suas cenas de infância, e de filmes como Oito e meio de Fellini (1963) com seu pôster do clássico filme italiano que, segundo Paulo Camargo, também inspirou All That Jazz - o show deve continuar e Nine, de Rob Marshall: "em todas essas obras, os personagens centrais se digladiam com o passado, que os impede de seguir em frente, de voltar a criar, mas também brigam com a condição de serem homens" (CAMARGO, 2019).

Em confronto dialético, podemos dizer que enquanto o documentário sobre David Lynch nos mostra um artista em ascensão, descobrindo seu potencial e suas possibilidades de expandir sua visão da pintura ao cinema, Dor e Glória nos mostra um cineasta revisitando seu passado, se autoanalisando e se culpando por algumas falhas, mas ao mesmo tempo recordando seus sucessos.

\section{Imagem e subjetividade}

Em relação aos conceitos de autorrepresentação e subjetividade, concordo com Alisa Lebow, editora do livro "The Cinema of me: the self and subjectivity in first person documentary", quando a autora menciona, na página inicial de sua Introdução, que os filmes em primeira pessoa podem ser completamente autobiográficos, ou só implicitamente ou

(U) parcialmente, desconstruindo a asserção de que documentários devem ser objetivos (LEBOW, 2012, p. 1). Diálogo também com Michael Chanan, em seu texto "The role of History in the individual: working notes for a film", onde o mesmo expande a noção de documentário em primeira pessoa incluindo biopics e citando Waiting for Fidel (1974), de Michael Rubbo, como um dos primeiros a apresentar o ponto de vista do diretor sobre 0 


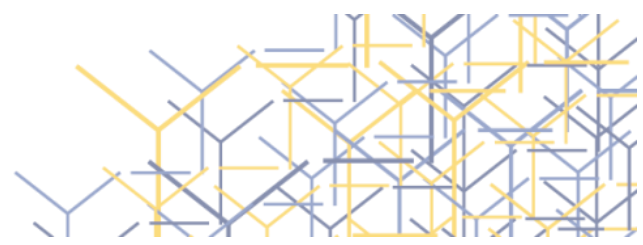

protagonista político, logo seguido por outros, como Nick Broomfield e Michael Moore, que constroem suas personas narcisisticamente (CHANAN, 2012 , p. 19). Manuela Penafria cita que, do mesmo modo como a ficção integra "elementos documentais", também no documentário há "elementos de ficção" (PENAFRIA, 1999, p. 28). A pesquisadora portuguesa complementa:

Acima de tudo, um documentário transmite-nos não a realidade (mesmo nos louváveis esforços em transmitir a realidade "tal qual") mas, essencialmente, o relacionamento que o documentarista estabeleceu com os intervenientes. No caso de documentários mais pessoais, o que é patente é a relação que o documentarista estabelece consigo próprio. (PENAFRIA, 2001, p. 8).

No caso do corpus deste estudo, ambos os documentários são subjetivos, se considerarmos que ambos se descrevem como querem ser vistos, mas talvez com uma diferença: Lynch nos mostra a origem de sua obra fílmica, enquanto Almodóvar, através de seu alter ego, nos revela sua angústia ao ver o quase término de sua vida de cineasta. Temos aqui os dois pólos se encontrando, ambos em suas tentativas de ascensão e reconciliação, respectivamente, que nos seduzem com suas imagensmemória e imagens-homenagem. Os diretores de David Lynch: A Vida de um Artista nos apresentam suas imagens-homenagem quando permitem que Lynch nos mostra suas pinturas e predileções por temas que são aplicados aos seus filmes. Almodóvar também nos oferece suas imagenshomenagem, especialmente quando se referem à sua mãe.

Em relação à montagem, ambos os filmes são subjetivos em revelar o que querem mostrar, talvez compactuando com Antonioni, quando este menciona que "um diretor não faz mais do que procurar-se em seus filmes - que são documentos não de um pensamento acabado, mas de um pensamento em desenvolvimento" (ANTONIONI, 1994, p. 57, tradução minha). Lynch escolhe com liberdade o que vai exibir, em saltos 
temporais entre pesadelos e imaginários, entre traumas menores da infância e escolhas que ecoaram em seus filmes. Almodóvar recorre à infância também, ao presente doloroso, aos sucessos e à incerteza do futuro. Ambos os documentários têm em comum mais um ponto relevante: são frutos de uma carreira brilhante, já reconhecida e cultuada.

\section{Considerações finais}

O presente estudo não ficaria completo sem uma menção ao status atual do documentário. Embora a trajetória desde o documentário clássico até o atual tenha trazido mudanças relevantes, menciono a voz de Bill Nichols, em seu livro Introdução ao Documentário, quando o autor faz uma analogia entre documentário e advogado, sendo que este representa os interesses de um cliente, isto é, argumenta sobre um ponto de vista ou uma determinada interpretação de provas:

[...] os documentários podem representar o mundo da mesma forma que um advogado representa os interesses de um cliente: colocam diante de nós a defesa de um determinado ponto de vista ou uma determinada interpretação das provas. Nesse sentido, os documentários não defendem simplesmente os outros, representando-os de maneiras que eles próprios não poderiam; os documentários intervém mais ativamente, afirmam qual é a natureza de um assunto, para conquistar consentimento ou influenciar opiniões. (NICHOLS, 2010, p. 30).

Continuando seu comentário sobre documentário, Nichols sugere que

[...] o peso que atribuímos à qualidade indexadora de som e imagem, a suposição que adotamos de que um documentário oferece prova documental na tomada, ou na palavra dita, não se estende automaticamente ao filme todo. Geralmente, entendemos e reconhecemos que um documentário é um tratamento criativo da realidade, não uma transcrição fiel dela.... o documentário reivindica uma 
abordagem do mundo histórico e a capacidade de intervenção nele, moldando a maneira pela qual o vemos. (NICHOLS, 2010, p. 67-69).

Embora Nichols possa estar se referindo a documentários clássicos, percebo que, mesmo na contemporaneidade, alguns documentários autobiográficos convergem na maneira como usam da sedução argumentativa para se apresentarem, embora com estratégias diversas. Em As praias de Agnès, já citado anteriormente, Varda declara abertamente e nos faz crer que aquela é sua vida, seu modo de pensar. Héctor Babenco, por outro lado, nega que seu filme Meu amigo hindu (2015) seja autobiográfico, mesmo quando todas as indicações provam o contrário. Sua estratégia é justamente a de fomentar um debate e talvez sugerir uma interpretação de que o cineasta Babenco não é o mesmo do indivíduo Babenco. Ambos os filmes usam da argumentação para assegurar que o que dizem traduz suas verdades.

No caso da análise dos dois filmes do corpus deste estudo, considerando que Lynch pode ser ele mesmo, expondo sua obra livremente, da maneira como Ihe foi permitido, e Almodóvar dirigiu seu próprio roteiro, há estratégias de subjetividade implícita ou explicitamente. No caso de Lynch, o encontro casual em sua infância com uma pessoa nua e desesperada, em prantos, é mencionado com certo exagero, para justificar a presença de temas e elementos estranhos em sua obra, contrários aos eventos de sua calma infância e juventude. No caso de Almodóvar, há também o exagero, chegando ao desmaio, ao ver um corpo masculino nu, em sua infância, o que justificaria sua homossexualidade latente.

Alisa Lebow sugere que "filmes em primeira pessoa podem ser poéticos, políticos, proféticos ou absurdos. Podem ser completamente autobiográficos, ou só implicitamente ou parcialmente. Podem tomar a forma de autorretrato, ou retrato de outro" (LEBOW, 2012, p. 1). Este comentário de Lebow se aplica ao corpus deste estudo. Ambos os filmes 
do corpus podem ser considerados poéticos. Além disso, assim como Velázquez se autorretratou como pintor, pintando uma obra, em seu quadro "Las Meninas", vemos Lynch pintando, vivenciando sua obra e nos oferecendo sua percepção de sua infância e juventude.

Por outro lado, Jean Jacques Rousseau explica em suas "Confissões":

Eis o que fiz, o que pensei, o que fui. Disse o bem e o mal com a mesma franqueza. Nada calei de mal, nada acrescentei de bom; e se me aconteceu usar algum ornato indiferente, não foi nunca para preencher um vácuo da minha falta de memória. Talvez tenha imaginado ser verdadeiro o que eu acreditava que o devesse ser, porém jamais o que eu soubesse ser falso. Mostrei-me tal qual era; desprezível e vil quando o fui; bom, generoso e sublime quando o fui, desnudei meu íntimo, tal como tu próprio o viste, Ente Eterno. (ROUSSEAU, 1959, p. 11).

Rousseau, tentando desfazer mal entendidos, ao explicar e reparar suas ações, complementa: "afinal não empreendi minhas confissões para calar minhas tolices e estas me revoltam muito para que me seja permitido dissimulá-las" (ROUSSEAU, 1959, p. 409). Da mesma maneira, Almodóvar se autoanalisa e se reconcilia.

Ao seguir a metodologia histórico-dialética de Gadamer, analisando ambos os lados dos pontos de vista, concordo com o autor sobre seu conceito de "fusão de horizontes", quando o mesmo menciona que "o horizonte do presente está sendo continuamente formado" e que o entendimento é a fusão do encontro do passado e do presente (GADAMER, 1999, p. 273). No caso deste estudo, argumento que os (U) documentários do presente, mesmo com suas subjetividades, serão a memória do futuro, seja esta formada por imagens-memória ou por imagens-homenagem. Ambos reforçam a memória coletiva e convergem em suas excessivas licenças históricas e artísticas. 
Concluo este estudo citando Arlindo Machado que, em relação ao documentário, em seu artigo "Novos territórios do documentário", diz que

\begin{abstract}
A bem da verdade, nenhum documentário é realmente um documentário puro. Aliás, um documentário puro seria algo inimaginável, pois sempre há uma interposição da subjetividade de um (ou mais) realizador(es), sempre são feitas escolhas, seleções, recortes e é inevitável que essas mediações funcionem como interpretações. Para o bem ou para o mal. Na verdade, o documentário puro nem é desejável, pois seria algo insípido, incolor e inodoro, além de inútil. (MACHADO, 2011, p. 24).
\end{abstract}

\title{
Referências
}

ANTONIONI, Michelangelo. Fare un film è per me vivere: scritti sul cinema. Venice: Marsílio Editori, 1994.

BACHELARD, Gastón. A Poética do Espaço. São Paulo: Martins Fontes, 1993.

BELLOUR, Raymond. Eye for I: Vídeo Self-Portraits. New York: Independent Curators Inc., 1989.

CAMARGO, Paulo. Dor e Glória é o mais pessoal dos filmes de Almodóvar. Escotilha, Curitiba, 18 jun. 2019. Disponível em:

http://www.aescotilha.com.br/cinema-tv/central-de-cinema/dor-e-gloriapedro-almodovar-resenha-critica/.

CHANAN, Michael. The Role of History in the Individual: Working Notes for a Film. In: LEBOW, Alisa (Org.). The Cinema of Me: The Self and Subjectivity in First Person Documentary. New York: Columbia University Press, 2012.

DAVID Lynch, A Vida de um Artista. Direção de Jon Nguyen, Rick Barnes e Olivia Neergaard-Holm. EUA/Dinamarca: Jon Nguyen, Jason S., Sabrina S. Sutherland, 2016. 1 DVD (1h 30m).

DELEUZE, Gilles; GUATTARI, Félix. Mil Platôs: capitalismo e esquizofrenia. São Paulo: Editora 34, 1980.

DERRIDA, Jacques. A Farmácia de Platão. 2 ed. São Paulo: Iluminuras, 1997. 


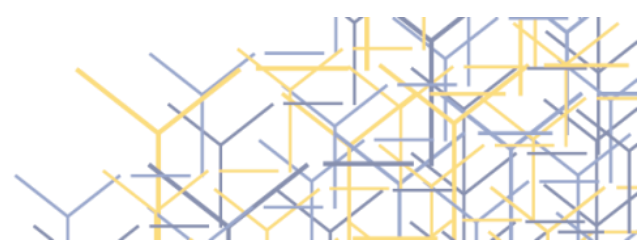

DOR e Glória. Direção de Pedro Almodóvar. Espanha: Universal Pictures, 2019. 1 DVD (1h 53m).

GADAMER, Hans-Georg. Verdade e Método - traços fundamentais de uma hermenêutica filosófica. 3 ed. Rio de Janeiro: Vozes, 1999.

HALBWACHS, Maurice. Memória Coletiva. 2 ed. São Paulo: Centauro, 2013.

LE GOFF, Jacques. História e Memória. 7 ed. Campinas: Editora Unicamp, 2013.

LEBOW, Alisa (Org). The Cinema of me: the self and subjectivity in first person documentary. New York: Columbia University Press, 2012.

MACHADO, Arlindo. Novos territórios do documentário. Doc On-line, Covilhã, n. 11, p. 5-24, dez. 2011. Disponível em: www.doc.ubi.pt/11/dossier arlindo machado.pdf.

MITCHELL, Thomas. What do pictures want? Illinois: University of Chicago Press, 2005.

NICHOLS, Bill. Introdução ao documentário. 5 ed. São Paulo: Papirus, 2010.

NORA, Pierre. Entre memória e história: a problemática dos lugares. Projeto História, São Paulo, n. 10, 1993.

PENAFRIA, Manuela. O filme documentário. História, Identidade, Tecnologia. Lisboa: Edições Cosmos, 1999.

POLLAK, Michael. Memória e identidade social. Estudos Históricos, Rio de Janeiro, v. 5, n. 10, 1992.

RICOEUR, Paul. A memória, a história e o esquecimento. Campinas: Editora Unicamp, 2010.

ROUSSEAU, Jean Jacques. As Confissões. 2 ed. São Paulo: Atena, 1959.

11 SARLO, Beatriz. Tempo passado: cultura da memória e guinada

(1) subjetiva. São Paulo: Cia das Letras, 2007.

TAVARES, Mirian. Do surrealismo de David Lynch. Revista ARS, São Paulo, v. 7, n. 14, p. 98-111, 2009. 
WARHOL, Andy. The philosophy of Andy Warhol (from A to B and Back again). Orlando: Harvest Book, 1975.

\section{Sobre a autora:}

Denize Araujo - PhD Comp Lit, Cinema \& Arts, UCR-USA. Pós-Doutorado UAlg, Portugal; Docente PPGCOM UTP; Coordenadora GT CIC (parceria com CIAC). Coordenadora do GT Imagem e Imaginários Midiáticos (Compós) e Visual Culture (IAMCR); Curadora do Animatiba - Festival Internacional de Animação de Curitiba e do FICBIC - Festival de Cinema da Bienal Internacional de Arte de Curitiba. Membro do IC, PC, SRC e Head da TF Inter/Actions da IAMCR. 